\title{
A prática pedagógica e seu entrelaçamento com as relações de gênero
}

\author{
Pedagogical practice and its training with gender relations
}

La práctica pedagógica y su entrella con las relaciones de género

\author{
Driéle Luize Souza da Silva ${ }^{1}$ \\ Juliana Brochado Da Luz ${ }^{2}$
}

Juliana Brandão Machado ${ }^{3}$

\begin{abstract}
Resumo
Pretende-se neste artigo apresentar o resultado de uma pesquisa que teve como objetivo problematizar as relações de gênero a partir das falas das alunas e dos alunos, na perspectiva de compreender o que dizem/pensam sobre a temática. Esse objetivo se construiu a partir da fala das alunas e alunos do quarto ano do ensino fundamental da escola Carlos Peixoto Primo na cidade de Rio Grande em 2017, que apresentavam conceitos que precisavam ser problematizados. O "Procedimento Metodológico" da pesquisa, levou em consideração a abordagem intervencionista do tipo pedagógica, utilizando a observação e a análise documental como instrumentos da coleta de dados. Os resultados mostraram que com a intervenção as crianças passaram a problematizar as questões de gênero em suas próprias falas como também as das outras crianças, porém ainda percebe-se que muitos padrões que são impostos pela sociedade se fazem presente nas falas e seus comportamentos.
\end{abstract}

Palavras-chave: Fala das alunas e alunos; Relações de Gênero; Prática Pedagógica; Pesquisa-intervenção; Problematização.

\begin{abstract}
This article intends to present the result of a research that had as objective to problematize the gender relations from the speeches of the students and the students, with a view to understanding what they say / think about the subject. This objective was constructed from the speech of the students and students of the fourth year of elementary school of the Carlos Peixoto Primo school in the city of Rio Grande in 2017, which presented concepts that needed to be problematized. The "Methodological Procedure" of the research, took into account the interventionist approach of the pedagogical type, using observation and documentary analysis as instruments of data collection. The results showed that with the intervention, children began to question gender issues in their own speeches as well as those of other children, but it is still seen that many patterns that are imposed by society are present in the speeches and their behaviors.
\end{abstract}

Keywords: Speaks of students and students; Gender Relationships; Pedagogical Practice; Intervention research; Problematization.

\section{Resumen}

Se pretende en este artículo presentar el resultado de una investigación que tuvo como objetivo problematizar las relaciones de género a partir de las palabras de las alumnas y de los alumnos, en la perspectiva de comprender lo que dicen / piensan sobre la temática. Este objetivo se construyó a partir del habla de las alumnas y alumnos del cuarto año de la enseñanza fundamental de la escuela Carlos Peixoto Primo en la ciudad de Rio Grande en 2017,

\footnotetext{
${ }^{1}$ Mestranda em Educação; Universidade Federal do Pampa, UNIPAMPA, Jaguarão; RS; Brasil; drile_rig@hotmail.com

${ }^{2}$ Mestre em Educação; UNIPAMPA; RS; Brasil; brochadodaluz@gmail.com

${ }^{3}$ Doutora em Educação (PPGEDU); Universidade Federal do Rio Grande do Sul, UFRGS, Brasil; juju.bmachado@gmail.com
} 
que presentaban conceptos que necesitaban ser problematizados. El "Procedimiento Metodológico" de la investigación, tuvo en cuenta el enfoque intervencionista del tipo pedagógico, utilizando la observación y el análisis documental como instrumentos de la recolección de datos. Los resultados mostraron que con la intervención los niños pasaron a problematizar las cuestiones de género en sus propias palabras y también las de los otros niños, pero todavía se percibe que muchos patrones que son impuestos por la sociedad se hacen presentes en las conversaciones y sus comportamientos.

Palabras clave: Habla de las alumnas y alumnos; Relaciones de género; Práctica pedagógica; intervención de la investigación; Cuestionamiento.

\title{
1. Introdução
}

Um dos maiores desafios da escola é garantir o respeito pelas diferenças sociais, culturais e individuais. Santos \& Paulino (2006, p. 11) postulam que: "Nos dias de hoje as desigualdades sociais e o desrespeito às diferenças são banalizados em nosso cotidiano, e a escola, sem dúvida, reflete e reproduz estas relações".

Pensando no que apontam os autores, o presente estudo tem como finalidade problematizar as relações de gênero a partir das falas dos alunos, procurando compreender se os recursos utilizados possibilitarão outra forma de entendimento sobre a temática. Para uma melhor compreensão, a definição que orienta esse estudo assume que:

\begin{abstract}
O termo "gênero" torna-se, antes, uma maneira de indicar "construções culturais" - a criação inteiramente social de idéias sobre papéis adequados aos homens e às mulheres. Trata-se de uma forma de se referir às origens exclusivamente sociais das identidades subjetivas de homens e de mulheres. "Gênero" é, segundo essa definição, uma categoria social imposta sobre um corpo sexuado. Com a proliferação dos estudos sobre sexo e sexualidade, "gênero" tornou-se uma palavra particularmente útil, pois oferece um meio de distinguir a prática sexual dos papéis sexuais atribuídos às mulheres e aos homens (SCOTT 1990, p.75).
\end{abstract}

A motivação por esta temática surgiu ao conhecer a turma de quarto ano, que trabalharia no período de 2017 e com o contato diário fui percebendo que algumas situações me deixavam bastante intrigada, muitas falas e atitudes eram carregadas de preconceito, discriminação e desrespeito. Conversei com colegas, que também percebem a mesma demanda, pois essa situação ganhava mais visibilidade na escola neste ano, e consequentemente percebemos a necessidade de trabalhar sobre as relações de gênero neste espaço.

Esta situação que se instalava na escola motivou-me a desenvolver a pesquisa a partir de dois fatores: um deles é a minha formação profissional como pedagoga e psicóloga, quando no decorrer destes cursos, desenvolvi alguns projetos referente às relações de gênero desde os anos iniciais até o ensino médio, como também com idosos e pessoas com câncer na 
Associação de Apoio a Pessoas com Câncer (AAPECAN), usando diferentes recursos como: dinâmicas, filmes, jogos e músicas, por acreditar que estes são aliados para transformar uma situação. O outro fator corresponde à atuação como docente dos anos iniciais do ensino fundamental de uma escola da cidade de Rio Grande, situada no bairro Querência, desejando qualificar minha prática pedagógica e continuar trabalhando com crianças. A possibilidade de cursar o Mestrado Profissional, que se volta para análise de intervenção no campo de trabalho, me propicia uma reflexão sobre o desenvolvimento da minha sala de aula.

Justifica-se este estudo por dois motivos principais: o primeiro foi perceber nas falas dos alunos uma problemática que podia ser melhor explorada, como por exemplo, "isso é coisa de menino", "isso é coisa de bichinha", "mulher não faz isso", "aquela menina tá rodada já, todo mundo fica com ela", "as meninas pedem pra tomar tapas, quando vem com short curto", "homem não chora", "quando crescer quero ter uma família legal, eu vou trabalhar e minha mulher vai ficar cuidando da casa, pois isso é coisa de mulher né professora", "meu pai não faz nada em casa só eu e minha mãe".

Já o segundo motivo provém do Projeto Político-Pedagógico (PPP) da escola, que tem como missão:

\begin{abstract}
Possibilitar uma ação educativa que contribua para a formação de um indivíduo autônomo capaz de organizar-se coletivamente, buscando alternativas para a construção de uma sociedade mais responsável, capaz de respeitar as diferenças étnicas, de classes, de gênero e religiosas que constituem os indivíduos e enriquecem as relações. Assim, a escola pretende atuar como um agente integrador da comunidade, despertando no aluno suas potencialidades e o espírito de sociabilidade e responsabilidade, a fim de prepará-lo para exercer sua cidadania, através da tomada de decisões conscientes, críticas e preservadoras do meio em que vive (PPP 2015, p.20 e 21).
\end{abstract}

Essa missão vem ao encontro da minha pesquisa e ao mesmo tempo que posso amenizar minhas angústias na sala de aula, também estou contribuindo para o cumprimento da missão da escola.

Após apresentar objetivo, motivação e justificativas que compuseram a minha pesquisa-intervenção, descrevo as subsequentes partes deste artigo. A primeira, intitulada a Perspectiva Teórica, que está subdividida na seguinte configuração: "A Constituição do Conceito de Gênero", em seguida "Gênero e Educação". Por fim, apresento o "Caminho Metodológico", os "Resultados da Pesquisa-Intervenção" e as "Considerações finais".

\title{
2. Tecendo a Perspectiva Teórica
}


$\mathrm{Na}$ presente seção, abordo o referencial teórico utilizado para respaldar a minha pesquisa-intervenção. O capítulo se inicia com "Gênero: traçando algumas considerações conceituais", cujo objetivo é tecer um panorama da construção do conceito de gênero que está entrelaçado em nossa sociedade, porém é recente sua visibilidade. Em seguida apresento a seção "Gênero e Educação", baseando-me na ideia de que as relações de gênero fazem parte do cotidiano escolar e são relações desiguais e marcadas pela diferença, precisando construir relações de gênero igualitárias.

\subsection{Gênero: traçando algumas considerações conceituais}

Somos educados para viver em uma sociedade que se constrói de forma distinta conforme o sexo, e isso pode ser visto desde a escolha do nome às atividades de lazer, reproduzindo-se continuamente, ou seja, se for menina atribui-se tudo a cor rosa envolvendo comidinha, "mamãe e filhinha" ou princesa a espera de um príncipe dentro de casa. Já se for menino é na rua com carros, jogos de luta ou sendo super-heróis e vestindo azul. Sustento essa ideia ancorada em Ribeiro e Soares (2007, p. 27), que postulam que as estereotipias de gênero estão compostas nos discursos: "meninos são fortes, jogam bola, usam roupa azul. Meninas são carinhosas, brincam de casinha, de boneca, usam roupa rosa, por exemplo,”. À medida que vamos crescendo, vamos nos construindo socialmente e aprendendo modos de ser e como se comportar como menino ou menina de acordo com os códigos de gênero que nos são "naturalmente" passados.

Ao delimitar o meu campo de estudo nesta pesquisa-intervenção, percebi a necessidade de me apropriar mais sobre o tema, me aprofundando nas teorias. Dessa forma busquei suporte através das autoras como Joan Scott, Judith Butler, Miriam Grossi, Guacira Louro dentre outras. Dialogar com essas autoras me permitiu compreender as relações de gênero como uma construção política, histórica, social e cultural abrindo um leque de entendimento que não se restringe somente ao biológico, o que me possibilitou refletir sobre a importância de abordar as relações de gênero na escola partindo dessa compreensão. Nesse sentindo, escrevi neste capítulo um panorama geral da constituição do conceito de gênero.

Nas últimas décadas é possível perceber algumas pessoas dizendo: "Mas isso é questão de gênero!", "O gênero e a política", "O gênero no trabalho", "o gênero feminino ou masculino", mas enfim, que gênero é esse que está envolvendo a fala das pessoas, o que elas e eles querem dizer com isso? 


\begin{abstract}
Na língua portuguesa a palavra 'gênero' apresenta inúmeros sentidos dependendo do campo do conhecimento em cujo discurso se insere. Entretanto, em termos gerais, gênero significa o conjunto de seres ou objetos que possuem mesma origem ou que se acham ligados pela similitude de uma ou mais particularidades. Em biologia, o termo se refere à categoria taxonômica que agrupa espécies relacionadas filogeneticamente, distinguíveis das outras por características marcantes que permitem assim a subdivisão das famílias. Na gramática, gênero se refere a classes de palavras que permitem estabelecer o contraste entre masculino e feminino, nem sempre referido a diferenças de sexo (BARATA, 2009,p. 73)
\end{abstract}

No entanto a citação acima conceitua gênero de uma forma geral, não ancorada em estudos feministas, por esse motivo aqui se fez necessária a exposição do conceito a partir desses estudos, fazendo um vínculo com a verbete da minha pesquisa. Segundo Tedeschi (2013, p.317):

O uso da palavra "gênero" tem sua história oriunda dos movimentos sociais de contestação a partir de grupos organizados de mulheres, feministas, sindicalistas etc. Sua trajetória que acompanha a luta por direitos civis e direitos humanos, enfim, acompanha a luta por igualdade e respeito.

Refletindo sobre a citação que conceitua o termo, penso que o gênero não se restringe a um único conceito, entendendo que é mais que uma dualidade entre os sexos, concordando com as palavras de Scott (1989, p.2): “os que se propõem a codificar os sentidos das palavras lutam por uma causa perdida, porque as palavras, como as ideias e as coisas que elas significam, têm uma história".

Para um melhorar o entendimento da importância da temática, se fez também necessário explicar como foram construídas as questões de gênero. Segundo Roiz (2011), mesmo que se possam considerar os avanços das últimas décadas, a história do gênero ainda está em construção, porém é percebido que houve um visível crescimento desse tema em pouco tempo, mas a consolidação desse campo de estudo ainda é muito recente.

Primeiramente, se faz necessário expor que o conceito de gênero era empregado de maneira desacertada, e Scott (1989, p.2) apresenta:

Mary Wortley Montagu acrescentava a ironia à sua denúncia do "belo sexo" ("meu único consolo em pertencer a este gênero é ter a certeza de que nunca vou me casar com uma delas") fazendo uso, deliberadamente errado, da referência gramatical. [...] "Não se sabe qual é seu gênero, se é macho ou fêmea, fala-se de um homem muito retraído, cujos sentimentos são desconhecidos". [...] "Atena não tinha nada do sexo, a não ser gênero, nada de mulher a não ser forma.

Scott (1989) consolida que ao longo dos séculos, as pessoas utilizavam de forma alusiva os termos gramaticais para nomear traços de caráter ou sexuais, um exemplo disso foi em 1876 no Dicionário de Língua Francesa que não designava o gênero, se era macho ou 
fêmea, fala-se de um homem bastante introvertido com sentimentos que até então não se conhecia ou se encaixava nos padrões já estabelecidos.

Percebi que a definição da palavra gênero, feita pelos franceses, ainda não ficava clara e não saía do viés da biologia, talvez houvesse somente uma troca de palavras, mas a abrangência do significado ainda não era percebida. Acredito que isso ainda esteja ancorado no binarismo que faz a distinção dos sexos.

As feministas americanas reconheceram o termo gênero no seu sentido literal, como uma forma de relacionar a organização social com a relação entre os sexos. A palavra apontava renúncia ao designo biológico que estava implícito no que diz respeito ao sexo ou diferença sexual. Meyer (2003, p. 25) salienta que ao ponderar sobre gênero, deve-se "pensar que há muitas formas de sermos mulheres e homens, ao longo do tempo, ou no mesmo tempo histórico, nos diferentes grupos e segmentos sociais". Em vista disso, é um entendimento que procura salientar a composição relacional e social das distinções entre os sexos, dissolvendo o determinismo biológico que aparece em algumas teorias.

Grossi (2000) aponta que no Brasil a palavra gênero ou relações de gênero como campo de estudo, surgiu na década de 1970 e 1980, entrelaçado com o descontentamento da condição feminina que até o momento não tinha visibilidade, apresentando-se também como consequência dos movimentos sociais de 1968 que lutavam por uma vida melhor, mais justa e igualitária. No entanto, as mulheres participantes perceberam que apesar de lutar igualmente com os homens, tinham um papel secundário e raramente assumiam uma liderança (Grossi, 1998).

Segundo Birman (2002), até o século XVIII o homem desempenhava um papel dominador e perfeito. Concomitante com a Revolução Francesa, surgiu como referência biológica o masculino superiorizado. Nessa visão homens e mulheres eram diferenciados e alocados em espaços distintos assim como o papel que desempenhavam socialmente era padronizado conforme a relação que estabeleciam entre si.

De acordo com Louro (1996), o conceito de gênero começou a ter visibilidade na década de 1980, articulando seu campo teórico com os estudos sobre a mulher, um tema que sofreu bastante resistência na universidade. Concomitante a isso, se fez necessário reorganizar o termo e dilatar o arquétipo tradicional existente. Segundo Scott $(1989$, p.7):

O gênero é igualmente utilizado para designar as relações sociais entre os sexos. O seu uso rejeita explicitamente as justificativas biológicas, como aquelas que encontram um denominador comum para as várias formas de subordinação no fato de que as mulheres têm filhos e que os homens têm uma força muscular superior. 
Embora este estudo já tenha conseguido um grande avanço, ainda há resistência ao que diz respeito às relações de gênero. Nos séculos XIX e XX, a condição de desigualdade das mulheres e outros grupos ficaram em evidência, a partir da ideia de "igualdade de direitos". Com todo esse movimento surge o conceito de gênero que aborda diferença e semelhança entre homens e mulheres a partir das construções sociais (Teixeira, 2010, p. 38). O conceito de gênero aponta os aspectos culturais como agente das diferenças entre os sexos, negando a origem biológica (Scott, 1990). Com isso:

Muda-se, radicalmente, o entendimento sobre comportamentos de homens e mulheres. Para além disso, tal visão criou a distância necessária entre os conceitos de sexo e gênero, humanizando aqueles que não se "encaixavam" propriamente ou "apropriadamente" nesses dois universos (masculino e feminino) tão rígidos (TEIXEIRA, 2010, p. 38).

A partir disso começa um novo viés no campo de estudo das relações de gênero. Se antes a diferença entre feminino e masculino era vista como algo pertencente só à biologia, passou pela fase de transformação ganhando mais entendimento sobre o seu conteúdo. Porém atualmente as relações de gênero em algum momento ainda se resumem em ser homem e ser mulher, pois essa questão está imbricada na sociedade e será uma luta contínua para ser modificada.

Butler (2012), faz uma crítica à construção histórica do gênero e à teoria feminista que construía uma identidade feminina, excluindo as mulheres que não se encaixariam nesse padrão e do quanto isso foi se naturalizando. Para a autora a história do gênero se construiu partindo de uma sociedade que mantém uma ordem compulsória que exige coerência, ou seja, quando a criança está na barriga da mãe, se tiver vagina, é menina e será condicionada a gostar de menino. Ainda segundo Butler (2012), o conceito de gênero construído estaria produzindo uma falsa noção de estabilidade, em que a heterossexualidade seria percebida como um padrão para sociedade, assegurando dois sexos, fixos e binários, macho e fêmea, excluindo quem não se identificasse como tal.

Para Scott (1992, p.14) o gênero é "um elemento constitutivo de relações sociais fundadas sobre as diferenças percebidas entre os sexos, e o gênero é um primeiro modo de dar significado às relações de poder”. Essas diferenças se organizam em uma linguagem culturalmente acessível com manifestações simbólicas e mitos. Conforme a autora, o gênero deve ser entendido como parte integrante da identidade dos sujeitos, tornando sua compreensão mais ampla e concordando com as ideias de Louro (1995, p.103), que diz que esse entendimento mais amplo: 
exige que pensemos não somente que os sujeitos se fazem homem e mulher num processo continuado, dinâmico (portanto não dado e acabado no momento do nascimento, mas sim construído através de práticas sociais masculinizantes e feminilizantes, em consonância com as diversas concepções de cada sociedade); [...] é mais do que uma identidade apreendida, é uma categoria imersa nas instituições sociais.

Nesse mesmo viés de construção mais ampla do gênero, ancoro-me na ideia de Butler (2012), que compreende que o gênero se constrói culturalmente não resultado do sexo e nem fixado a ele, sendo mutável, ou seja, uma pessoa com um corpo nomeado feminino não necessariamente perceber-se-á como mulher, da mesma forma pode acontecer com o corpo masculino, distanciando-se do fator biologicista.

Ancorada nesses entendimentos, percebi que seria difícil uma única definição sobre gênero, pois este não se limita a um viés, ele vai além do que podemos definir, mas podemos entender que: "gênero é algo que 'fazemos' e não algo que 'somos' naturalmente, mas sim, uma estrutura imaginada pelos desejos-condicionados" (BUTLER, 1999, p.65, grifos da autora). Ainda segundo a autora, "o gênero não deve ser meramente concebido como uma inscrição cultural de significado num sexo previamente dado [...] tem de designar também o aparato mesmo de produção mediante o qual os próprios sexos são estabelecidos" (BUTLER, 2003, p. 25).

Conforme Matos (1997), falar sobre gênero é dizer que os perfis masculinos e femininos se determinam um à visão do outro.

[...] perfis se constituem social, cultural e historicamente num tempo, espaço e cultura determinados. Não se deve esquecer, ainda, que as relações de gênero são um elemento constitutivo das relações sociais baseadas nas diferenças hierárquicas que distinguem os sexos e são, portanto, uma forma primária de relações significantes de poder. Sendo uma de suas preocupações evitarem as oposições binárias fixas e naturalizadas, os estudos de gênero procuram mostrar que as referências culturais são sexualmente produzidas, por meio de símbolos, jogos de significação, cruzamentos de relações de gênero (MATOS, 1997, p. 97- 98).

Diferentes autores fazem uma definição que facilita o entendimento do conceito de gênero. Assim, Saffioti, (1992, p.190) contribui afirmando que:

[...] tanto o gênero quanto o sexo são inteiramente culturais, já que o gênero é uma maneira de existir do corpo e o corpo é uma situação, ou seja, um campo de possibilidades culturais recebidas e reinterpretadas. Nesta linha de raciocínio, o corpo de uma mulher, por exemplo, é essencial para definir sua situação no mundo. Contudo, é insuficiente para defini-la como mulher. Esta definição só se processa através da atividade desta mulher na sociedade. Isto equivale a dizer, para enfatizar, que o gênero se constrói - expressa através das relações sociais.

Fiz uma reflexão sobre a grandiosidade dessa temática e percebi o quanto é possível envolvê-la em diferentes áreas como História, Filosofia, Sociologia e entre outras disciplinas que fazem parte da educação, conseguindo articular-se por diversos significados de acordo 
com a área predominante, sendo possível de ser compreendida como interdisciplinar pra quem quer e consegue enxergar as relações de gênero na escola. Por este motivo o próximo capítulo entrelaça Gênero e Educação com o intuito de esboçar os seus laços com a educação e a minha prática pedagógica.

\subsection{Gênero e Educação}

Quando se fala na relação entre gênero e educação, diferentes questões podem ser apontadas desde a história até os dias atuais, dentre elas a distinção de gênero, que supostamente pode ser percebida pela composição da sociedade brasileira que está marcada pelo patriarcado, relações de poder e autoritarismo que repercutem na educação formal, com um histórico de exclusão das mulheres, como afirmam Beltrão e Alves (2004, p.3-4):

A economia colonial brasileira fundada na grande propriedade rural e na mão-de-obra escrava deu pouca atenção ao ensino formal para os homens e nenhuma para as mulheres. O isolamento, a estratificação social e a relação familiar patriarcal favoreceram uma estrutura de poder fundada na autoridade sem limites dos homens donos de terras.

Essa situação começa a se reestruturar em outra perspectiva, após a Revolução de 1930, quando apontam as primeiras ações direcionadas para a educação estendendo também o acesso das mulheres à escola. Todavia apenas com a Lei de Diretrizes e Bases da Educação Nacional (LDBEN), exatamente em 1961, foi assegurado o acesso igualitário ao ensino superior para as mulheres que frequentavam o magistério, através da equivalência dos cursos de nível médio (BELTRÃO E ALVES, 2004).

E hoje, a educação mudou? Sobre as relações de gênero na escola, o que mudou? Ainda que estudos comprovem um avanço relacionado a este tema, é preciso aprofundar e abordar mais o assunto, pois por vezes diferentes situações de desigualdade, preconceito e discriminação, passam pelos nossos olhos de forma naturalizada, deixando de problematizar tal questão. Segundo Vianna (2004, p.78):

[...] poucas são as investigações que abordam o impacto da discriminação de gênero nas políticas públicas educacionais, tais como a persistência da discriminação contra as mulheres expressa em materiais didáticos e currículos, a limitação ao acesso à educação e permanência na escola, sobretudo das jovens grávidas, bem como o fracasso escolar que marca de maneira distinta a trajetória escolar de meninos e meninas. 
A escola é um lugar com inúmeras possibilidades de trabalhar, valorizar e respeitar diferenças seja através de seu universo coletivo, seja da unicidade, não importa de que forma, qualquer uma pode propiciar o reconhecimento de si e do outro, partilhando significados afins ou não. Ainda assim mesmo com esse espaço tão rico, muitas vezes diferentes situações perpassam de forma habitual e não são questionadas, contribuindo para irradiação das diferentes formas de preconceito, discriminação, desigualdade e exclusão.

As escolas se constituem como espaços fundamentais para a socialização dos/as jovens e muitas vezes nelas são reproduzidas relações de poder que incluem práticas machistas e sexistas. Acreditamos que as pesquisas que se interrogam sobre o cotidiano escolar devem estar preocupadas em perceber como a presença de estereótipos de gênero pode acentuar situações de preconceito e discriminação nas escolas (PULCINO, 2014, p. 129).

Segundo Teixeira (2010) a escola pode ser vista como um grupo vivo que transpassa estereótipos, mas que também de forma autárquica pode estabelecer algum modelo de comportamento. Assim sendo alguns acontecimentos escolares e a maneira como os sujeitos os vivenciam, serão efeito do conflito em diferentes subgrupos dentro da escola como: alunos, professores, gestores, pais dentre outros grupos importantes nesse ambiente.

No Brasil existem algumas ações que dão sustentação para trabalhar as questões de gênero na educação. Um exemplo disso é o projeto "Gênero e educação: fortalecendo uma agenda para as políticas públicas ${ }^{4}$.O projeto foi ancorado no diagnóstico e recomendações contidas no Informe Brasil, cujo o objetivo foi:

contribuir para fortalecer o lugar da agenda de gênero nas políticas educacionais brasileiras, em suas intersecções com raça e sexualidade. Buscou incidir tanto na gestão pública como junto aos movimentos sociais de educação, feminista, LGBT, sindicais, entre outros (CARREIRA, 2014, p.13).

Segundo Carreira (2014, p.13), "No Brasil, o Projeto constituiu um dos desdobramentos da Campanha Latino-americana por uma Educação não sexista e antidiscriminatória, impulsionada pelo CLADEM entre os anos de 2009 e 2011 ”. Ações assim impulsionam para pensar em uma educação mais igualitária, mostrando que as temáticas que entrelaçam as relações de gênero fazem parte do cotidiano escolar.

\footnotetext{
${ }^{4}$ Este projeto foi desenvolvido entre os anos de 2014 a 2016, pela Ação Educativa com a parceria das organizações do Comitê da América Latina e do Caribe para a Defesa dos Direitos da Mulher, EcosComunicação em Sexualidade e Géledes - Instituto da Mulher Negra. Além das quatro organizações de sociedade civil, com a participação do Departamento de Pesquisas Educacionais da Fundação Carlos Chagas.
} 
No Informe, Carreira (2014, p. 29 e 30) afirma que "promoção da equidade de gênero nas políticas educacionais deve contemplar":

políticas que garantam o acesso e a permanência de todas as mulheres e homens à educação formal e o direito à aprendizagem[...]; políticas que ampliem a noção vigente de qualidade em educação[...]; políticas que promovam um maior equilíbrio entre mulheres e homens no acesso às instâncias de poder na educação[...]; políticas intersetoriais, da qual a educação esteja articulada a políticas de distribuição de renda, trabalho, saúde, proteção, etc, concretizando a natureza integral e indissociável dos direitos humanos[...].

Mesmo que existam políticas corroborem para abordar as relações de gênero na educação, é possível ainda concordar com Louro (1997, p.110) que aproximadamente há duas décadas escreveu que: "os processos escolares como formadores e reprodutores de desigualdades sociais vêm ocupando a agenda política e acadêmica de muitas estudiosas e estudiosos críticas/os há várias décadas".

De maneira geral desconstruir estereótipos de gênero não pode ser considerada uma tarefa fácil e possível de ser feita repentinamente, esse processo deve ser contínuo, elaborando estratégias que promovam debates sobre gênero. Também é necessário, possibilitar "debates sobre o processo histórico e social de transformação das diferenças em desigualdades e de naturalização ou de invisibilidade dessas desigualdades" (Pulcino, 2014, p. 129). Considera-se essencial um posicionamento da educação, que possa interpelar os significados que foram impostos para homens e mulheres, que perpassam ao longo dos anos como arquétipos, ou seja, um modelo a ser reproduzido por nossa sociedade. Concordando com a ideia de Pulcino (2014, p. 129):

\footnotetext{
Assim, não basta apenas reconhecer que existem diferentes expectativas para mulheres e homens, mas também perceber por meio de quais mecanismos sociais o controle dos corpos é reiterado ao longo da vida escolar dos/as estudantes, de modo a desvela-los e tornar o tratamento dos gêneros mais igualitário.
}

Pensando nas palavras de Pulcino, é possível perceber que em muitos espaços escolares existe uma preocupação em relação ao comportamento das alunas e alunos de forma cautelosa redireciona o grupo para uma conduta aceita pela sociedade. Dessa forma, intencional ou não, estabelece a continuação da desigualdade de gênero. Na relação existente na escola com a construção das identidades das/os sujeitos e na estabilização das diferenças, Meyer e Soares (2004, p.8) afirmam que: 
Desde sua constituição, a escola é marcada por diferenças e está implicada, também, com a produção dessas diferenças. Embora não seja possível atribuir a ela toda a responsabilidade pela construção das identidades sociais, ela continua sendo para crianças e jovens um local importante de vivências cotidianas específicas e, ao mesmo tempo, plurais.

Nessa mesma perspectiva, Alvarez-Uría e Varela (2009) postulam que a escola não exibe as diferentes formas de desigualdade explicitamente, porém muitas vezes ratifica, permitindo que em seus diferentes espaços transitem normas da sociedade, transmitidas pela própria comunidade escolar, uma vez que situações de desigualdade já estão imbricadas na instituição. Segundo Louro (1999, p.58): “a escola delimita espaços. Servindo-se de símbolos e códigos, ela afirma o que cada um pode (ou não pode) fazer, ela separa e institui. Informa o "lugar" dos pequenos e dos grandes, dos meninos e das meninas".

Existe também uma resistência por parte de alguns profissionais para trabalhar as relações de gênero, seja por sua construção pessoal ou até mesmo por insegurança ou falta de informação, já que hoje há um retrocesso em relação a essa temática, que está socialmente distorcida por grupos que a compõe como religiões, política, veículos de comunicação entre outros. Hoje a tarefa de falar sobre essa temática fica muitas vezes restrita às aulas de biologia, ou melhor, através desse componente é que existe a possibilidade de relacionar essa temática, quando se trata de sexualidade, prevenção. No entanto posicionar-se frente aos temas que entrelaçam as relações de gênero, contribui de maneira positiva na formação das alunas e alunos, desconstruindo barreiras do preconceito e discriminação existente nesse espaço.

Embora que os estudos sobre gênero tenham avançado e construído um espaço na educação, contribuindo para igualdade de diretos, ainda é possível perceber que estão imbricados na fala e na conduta de alunas e alunos, diferentes formas de preconceito, sendo esses trazidos do contexto em que estão inseridos e também por mobilizações para retirado do gênero dos Planos de Educação em nível nacional, regional e local repercutindo de uma forma negativa em todo o valor desse estudo, o que estagna e até mesmo causa um retrocesso da inserção dessa temática na escola, de uma maneira clara e consciente.

Com o intuito de repensar sobre determinados comportamentos e falas que se mostram discriminatórias é preciso ficar atento às diversas circunstâncias que surgem no cotidiano, e problematizá-las dando conta no que diz nos documentos legais que entrelaçam as relações de gênero. Ao concluir essa discussão teórica, percebo que foi de suma importância buscar um aprofundamento teórico sobre a temática, para que eu pudesse continuar na caminhada contra a desigualdade, já que a escola é um lugar onde as relações acontecem e, infelizmente, a 
igualdade não prevalece. Porém, reconheço que muitas questões ainda ficarão sem respostas, que o processo de apropriação deste tema é uma construção permanente e penso que carregarei comigo estas leituras e as próximas que virão, para meu crescimento pessoal e profissional. Com base nas leituras feitas e nas minhas inquietações, exponho a seguir o caminho metodológico da minha pesquisa-intervenção.

\section{Procedimentos Metodológicos}

\subsection{Engendrando os caminhos}

A pesquisa empenhou-se em desenvolver atividades que partiam da realidade do local articulando com a demanda que a turma apresentava, em uma abordagem social e de cunho qualitativo, onde o foco principal era a vivência das/os alunas/os produzindo dados que responderam aos objetivos ou não.

Por se tratar de uma pesquisa em que pude interagir com a finalidade de envolver ainda mais os/as alunos/as, estimulando-os/as a participarem ativamente durante todo o processo, consegui analisar metodologicamente os dados que surgiram e logo depois avaliar, empregando uma abordagem do tipo pedagógica. Segundo Damiani et al. (2013) nesse tipo de pesquisa, o pesquisador deve planejar e intervir, com o intuito de acarretar avanços que originam efeitos e ainda no relato de pesquisa deve haver dois elementos principais:

O método da intervenção deve ser descrito pormenorizadamente, explicitando seu embasamento teórico. (...) Aqui, o foco do autor do relatório deve estar voltado somente à sua atuação como professor (agente da intervenção). O método de avaliação da intervenção tem o objetivo de descrever os instrumentos de coleta e análise de dados utilizados para capturar os efeitos da intervenção. (...) tendo o foco na atuação do autor como pesquisador. A avaliação da intervenção (...) é igualmente composta por dois elementos: os achados relativos aos efeitos da intervenção sobre seus participantes e os achados relativos à intervenção propriamente dita (DAMIANI et al.,2013, p. 62, grifos dos autores).

Com base na metodologia apresentada, planejei minha sala de aula, construindo um novo olhar ao meu modo de ser professora e pesquisadora, reavaliando conceitos já estabelecidos, intervindo na construção de possibilidades de articular as relações de gênero com as/os alunas/os na medida em que tenho a oportunidade de me aproximar de sua cultura e de sua história.

Acreditando que por meio do registro seja disponibilizado, dentre tantos ganhos, a construção de novas e diferentes aprendizagens que se originam através das curiosidades, 
indagações e experiências de vida dos grupos, juntamente com minhas inquietações, problematizações e desafios, propus utilizar um portfólio individual (que foi nomeado como álbum na abordagem em sala de aula), fotos e gravações para registrar atividades que terão como recursos: livros, jogos, brincadeiras dirigidas, brinquedo, música e filme para abordar as questões de gênero no grupo.

As atividades para as intervenções foram elaboradas a partir do desenvolvimento de diversas observações. Segundo Negrine (1999; p.67) “deve ser contínua e sistemática com a função de registrar determinados fenômenos ou comportamentos. Para tanto é necessário que seja: a) intencionada: com objetivos determinados; b) sustentada: guiada por um corpo de conhecimentos". Nessa ocasião tive a oportunidade de perceber quais atividades as/os alunas/os mostraram-se mais atraídas/os e assim planejei-as com mais proximidade às suas realidades. As intervenções foram desenvolvidas sendo planejadas em três momentos, com duração de cerca de duas horas ao todo:

Momento inicial: ocorreu uma conversa explicando a proposta que foi desenvolvida e apresentação do recurso utilizado. Neste momento instigou-se as/os alunas/os, falando sobre o nome do recurso, com o objetivo de chamar sua atenção para a atividade. Segundo Yozo (1996) o grupo se prepara, combina a aula dessa maneira. Aqui também ressalta-se a importância da participação de todas/os para o bom desenvolvimento do trabalho.

Momento: neste momento o recurso foi apresentado e feito alguns questionamentos que desencadearam as discussões, como: de que se trata? A quem se destina? O que acontece? Isso também pode acontecer na vida da gente? Como? Qual é o desfecho? Qual seria a outra possibilidade? O que tu farias se passasse tal situação? Neste momento problematizou as respostas das/os alunas/os ajudando-as/os a questionar suas opiniões já formadas ou a (re)construção de seus entendimentos, tudo oralmente e ainda em círculo. $3^{\circ}$

Momento: A produção e apresentação do entendimento das/os alunas/os. Neste momento foram disponibilizados materiais para a construção do portfólio (álbum) na sequência, em círculo, cada um narra o que escreveu. A atividade não dirigida pelo professor faz com que o grupo "acione o tempo todo mecanismos de pensamentos, 
seja para realizar movimentos técnicos ou simbólicos, seja para imitar os iguais, seja para experimentar novas situações" (NEGRINE, 2002, p.152).

Foi uma premissa desta abordagem que desde o início da atividade as/os alunas/os se sintam desafiadas/os, mas sem conduzir para uma forma específica de como desenvolver, isto é, encorajar a participar dando suporte para suas próprias realizações. No seguimento do relatório, coloco a busca de caminhos para a intervenção.

\section{Trilhando os caminhos: a intervenção pedagógica}

Levando em consideração as minhas inquietações e percebendo a necessidade de desenvolver atividades atrativas com a turma, apresento a intervenção pedagógica que foi realizada através de atividades diversificadas a fim de atingir meu objetivo, problematizar as relações de gênero presentes na turma. Foram realizadas oito atividades, com duração em média de 2 horas e meia cada uma com intervalo de dois ou quatro dias dependendo percepção que se tinha em necessitar dar sequencia seguidamente ou não. O horário dessas atividades aconteceu dentro da carga horária de aulas no período da tarde. As atividades foram gravadas em áudio através de um aparelho telefônico, enquanto as crianças estavam interagindo entre si e comigo, com o intuito de auxiliar na coleta de materiais para análise posterior. A seguir, apresento a tabela com as atividades que foram desenvolvidas com os principais objetivos.

Tabela1: As atividades de intervenção

\begin{tabular}{|l|}
\hline $\mathbf{1}^{\circ}$ Atividade:Estreitando os laços com a pesquisa \\
Objetivo: Apresentar a pesquisa-intervenção \\
\hline $\mathbf{2}^{\circ}$ Atividade:Desapegando dos estereótipos: cada um desenha o personagem que quiser \\
Objetivo: Construir um personagem livre dos padrões impostos pela sociedade. \\
\hline $\begin{array}{l}\mathbf{3}^{\circ} \text { Atividade: Jogos e brincadeiras de meninos e meninas: isso existe mesmo? } \\
\text { menina. }\end{array}$ \\
\hline $\mathbf{4}^{\circ}$ Atividade:Caracterizando coisas e pessoas \\
Objetivo: Problematizar padrões de comportamentos. \\
\hline $\mathbf{5}^{\circ}$ Atividade:Vídeo desafio da igualdade \\
\hline
\end{tabular}


Objetivo: Refletir sobre os desafios impostos pela sociedade.

$6^{\circ}$ Atividade: Quem disse que não pode?

Objetivo: Refletir sobre o modo de ser menina e menino.

$7^{\circ}$ Atividade: Profissões

Objetivo: Promover discussão sobre as profissões ditas de homem ou mulher.

$\mathbf{8}^{\circ}$ Atividade: Retomando as atividades

Objetivo: Relembrar e problematizar todas as temáticas entrelaçadas nas relações de gênero.

Fonte das autoras

\section{Conduzindo aos resultados: a avaliação da intervenção}

Para designar a minha pesquisa como intervenção foi necessário que no método da avaliação da intervenção acontecesse um planejamento de acordo com a realidade e necessidade do grupo, repensando também quais instrumentos seriam utilizados para sua efetivação. Segundo Damiani et al. (2013), a avaliação da intervenção, na especificidade dessa pesquisa, deve esboçar os instrumentos de coleta e análise de dados e justificar seu propósito, assim como explorar os resultados conseguidos. Portanto, para avaliar essa intervenção procedi com os seguintes instrumentos: análise documental e observação.

Delineei previamente que os documentos para análise seriam os álbuns produzidos pelos sujeitos envolvidos, minhas observações, gravações e anotações.

A primeira decisão nesse processo é a caracterização do tipo de documento que será usado ou selecionado. (...) Será do tipo oficial (por exemplo, um decreto, um parecer\}, do tipo técnico (como um relatório, um planejamento, um livro-texto) ou do tipo pessoal (uma carta, um diário, uma autobiografia)? Envolverá informações de arquivos oficiais ou arquivos escolares? Ou ambos? Será um material instrucional (filme, livro, roteiro de programa) ou um trabalho escolar (caderno, prova, redação)? Incluirá um único tipo desses materiais ou uma combinação deles? (LUDKE, ANDRÉ, 1986, p. 40).

Já em relação as minhas observações sustento-me na ideia de que é uma técnica em que se pode usufruir dos sentidos para o atingimento de determinadas informações da realidade, considerando ou não os fatos ou fenômenos que se deseja seguir (Lakatos e Marconi, 2010). Segundo as autoras, a observação é sistemática quando dispõe recursos para a coleta dos dados observados e o observador compreende o que procura. No que se refere ao procedimento, é estabelecida como observação participante, quando o observador se apresenta 
de forma adjunta e participa das ações do grupo. Ainda em relação às observações, realizei em todos os momentos das atividades e posteriormente elaborei o registro no diário de campo tendo as gravações em áudio como suporte, baseando-me na afirmação de Ludke, Andre (1986, p. 32).

Há formas muito variadas de registrar as observações. Alguns farão apenas anotações escritas, outros combinarão as anotações com o material transcrito de gravações. Outros ainda registrarão os eventos através de filmes, fotografias, slides ou outros equipamentos.

Com a finalidade de análise dos dados desta pesquisa foi utilizado o procedimento de análise textual discursiva (qualitativa).

[...] a análise textual qualitativa pode ser compreendida como um processo autoorganizado de construção de compreensão em que novos entendimentos emergem de uma sequência recursiva de três componentes: desconstrução dos textos do corpus, a unitarização; estabelecimento de relações entre os elementos unitários, a categorização; o captar do novo emergente em que a nova compreensão é comunicada e validada (MORAES, 2003, p. 192).

De acordo com Moraes (2003), na análise textual discursiva o propósito é descrever e interpretar sentidos e significados a partir dos materiais analisados, atingindo uma compreensão cada vez mais profunda dos significantes dos fenômenos estudados. Em vista disso, dando seguimento, apresento as categorias que surgiram da análise dos dados obtidos.

\section{Considerando Os Dados: a Análise Da Intervenção}

No sentido de estabelecer a análise foi necessário fazer uma nova leitura, reexaminar ideias e atentar novamente aos registros e relatos com o objetivo de aprofundar a leitura e reorganizar o material, de forma que meu objetivo como pesquisadora fosse atingido o melhor possível, pois

Exercitar uma leitura aprofundada é explorar uma diversidade de significados que podem ser construídos com base em um conjunto de significantes. É ainda explorar significados em diferentes perspectivas, valendo-se de diferentes focos de análise. [...] Por mais sentidos que se consiga mostrar, sempre haverá mais sentidos. (MORAES, 2003, p.196).

Dessa forma, com as ideias recorrentes destacadas a partir do que mais foi estudado e revisão dos instrumentos da pesquisa, foram estabelecidas duas categorias. A primeira categoria foi intitulada como "Binarismos de Gênero e as suas Repercussões para a 
Educação" em que se pretendeu expor o quanto o binarismo está construído de forma naturalizada, dentro e fora da sala de aula e muitas vezes não percebemos, mas estamos tramados em diferentes padrões impostos de maneira cultural na sociedade. A segunda categoria foi denominada como "É possível a discussão de gênero na sala de aula? Tecendo algumas possibilidades dessa abordagem". Essa categoria apresentou estratégias de problematizar as questões de gênero que aparecem na sala de aula, sem necessariamente ter uma atividade específica, mas através da fala das alunas, alunos de acordo com suas experiências e contextos ambientais. Essas categorias foram construídas a partir da associação das informações por semelhança, comparando-as entre si, uma vez que: "Esse é um processo essencialmente indutivo, de caminhar do particular ao geral, resultando no que se denomina as categorias emergentes". (MORAES, 2003, p.197).

\section{Considerações Finais}

Este artigo apresentou um recorte da pesquisa-intervenção que teve como objetivo problematizar as relações de gênero a partir das falas das alunas e dos alunos, na perspectiva de compreender o que dizem/pensam sobre a temática. No início da intervenção, acreditei que não avançaríamos muito com a compreensão da temática, pois muitos pareciam resistir em falar alguma coisa, porém o tempo foi passando e a cada intervenção eu notava as/os alunas/os mais envolvidos, fazendo reflexões e questionamentos, o que me deixa bem contente, pois acredito que o objetivo geral foi atingido, assim como os objetivos específicos tais como: discutir sobre as relações de gênero; participar de atividades, conversas e brincadeiras envolvendo as relações de gênero; observar e analisar os registros dos encontros com os alunos, o que pode ser percebido ao longo intervenção.

Sobre as categorias que surgiram da pesquisa, o resultado da análise de dados possibilitou duas vertentes, a primeira intitulada: Binarismos de Gênero e as suas Repercussões para a educação, em que procurei apresentar diferentes situações de dentro e fora da sala de aula, através da fala das/os alunas/os, que definem a necessidade de discussão sobre gênero. O binarismo e os estereótipos se destacaram pelo acumulo conceitual que se formou o que significa que ele persiste no cotidiano escolar e acredito no contexto familiar também assim como a questão de abordar as relações que entrelaçam o gênero, que por vezes perpassam e não são problematizadas.

A segunda categoria foi construída como uma pergunta: "É possível discutir gênero na sala de aula? Tecendo algumas possibilidades de abordagem", e ao longo do texto vou 
mostrando as possibilidades de abordar esses temas, compreendendo que não é preciso ter uma atividade específica, mas também um olhar atento a demanda que a turma apresenta e trabalhar em cima da realidade, buscando autores que fortalecem a intervenção.

Metodologicamente, a pesquisa intervencionista do tipo pedagógica, oportunizou o desenvolvimento do meu papel como professora e pesquisadora, que necessita realizar as intervenções e coletar dados através dos instrumentos, que foram a observação e a análise documental. Dessa forma, na primeira fase da pesquisa foi possível desenvolver a intervenção com um olhar atento à ocorrência de falas e comportamentos que possibilitassem a problematização das relações de gênero. A partir das observações percebi que as problematizações que eram lançadas, logo as respostas não eram mais tão rápidas e muitas vezes falavam por impulso, por muitos havia uma reflexão do que iriam falar ou então me questionavam para saber minha opinião. A análise documental proporcionou a exposição dos entendimentos das crianças que se dedicaram para desenvolver cada atividade.

Com relação à intervenção desenvolvida com as crianças da turma do quarto ano do ensino fundamental da Escola Pedro Carlos Peixoto Primo, no ano de 2017, percebi que nossas discussões conseguiram produzir reflexões relevantes ao longo da intervenção, sobre os conceitos que até o momento haviam sido construídos através dos contextos social, familiar e escolar.

Acredito que esta pesquisa contribuiu para uma reflexão sobre a inserção da temática gênero como uma proposta de trabalho na sala de aula, usando uma metodologia com atividades diversificadas, para que seja um trabalho mais agradável para os sujeitos envolvidos. É preciso repensar sobre como as relações de gênero acontecem no ambiente escolar e promover um espaço para que as diferentes questões que entrelaçam essa temática possam ser problematizadas.

O estudo que envolveu a pesquisa e a experiência de problematizar implicações que acontecem por quem defende as discussões de gênero na sala de aula trouxe algumas mudanças, entre elas: o reconhecimento da importância de não deixar passar situações e comportamentos que envolvem desigualdade e preconceito, pois a criança reproduz aquilo que ela aprende, que para ela é o certo, mas não recebeu de nenhum lado algum questionamento, uma reflexão. Também o cuidado em manter a atenção das crianças com atividades diversificadas, dentro da realidade em que se está inserida e acreditar mais ainda que exista sempre um caminho para atingir nossos objetivos, se de uma maneira não se obteve progresso então é preciso observar e traçar novos caminhos. 
Todo o processo que envolve a pesquisa do tipo intervenção pedagógica propõe a reflexão de que, enquanto pesquisadora, é possível ser mais atuante e trazer as demandas reais da escola para a universidade e assim, estabelecer um diálogo mais próximo e produtivo. Essa característica e diferença do mestrado profissional definiram a qualidade, a aprendizagem e a relevância da proposta e me sinto muito privilegiada de fazer parte desse processo.

\section{Referências}

BARATA, Rita B. Relações de gênero e saúde: desigualdade ou discriminação? In:Como e por que as desigualdades sociais fazem mal à saúde [online]. Rio de Janeiro: Editora FIOCRUZ, 2009. Temas em Saúde collection, pp. 73-94. ISBN Books <http://books.scielo.org>.Acesso em: 20 de maio/2017

BELTRÃO, Kaizô.I; ALVES, J.E.D. A reversão do hiato de gênero na educação brasileira no século XX. ABEP, 2004. Disponível em

http://www.metas2015.unb.br/Documentos/Educacao\%20Universal/Reversao\%20do\%20hiat o\%20de\%20genero\%20na\%20educacao.pdf. Acesso em: 26 de maio/2017

BIRMAN, Joel. (Org.) “ $O$ encontro entre a psicanálise e o feminino: singularidade e diferença. Rio de Janeiro: Contra Capa, 2002

BUTLER,Judith. Problemas de Gênero. Feminismo e subversão da identidade. Rio de Janeiro, Civilização Brasileira, 2012.

CARREIRA, Daniel. [et al.]. Gênero e educação: fortalecendo uma agenda para as políticas educacionais São Paulo : Ação Educativa, Cladem, Ecos, Geledés, Fundação Carlos Chagas. 2016.

DAMIANI,Magda. F.; ROCHEFORT, Renato Siqueira; CASTRO, Rafael Fonseca de; DARIZ, Marion Rodrigues; PINHEIRO, Silvia Siqueira. Discutindo pesquisas do tipo intervenção pedagógica. Cadernos de Educação FaE/PPGE/UFPel. Pelotas, n. 45, p. 57-67, jul./ago. 2013.

GROSSI, Miriam. P. Identidade de gênero e sexualidade. Estudos de Gênero.Cadernos de Área, n. 9, Programa Interdisciplinar da Mulher-Estudos e Pesquisas. Goiânia: UCG, 2000.

LOURO, Guacira. L. Nas redes do conceito de gênero. In: Lopes, M.J.D.;Meyer, D>E>; Waldow,V.R,(orgs). Gênero e saúde. Porto Alegre, RS: Artes Médicas, 1996. 
,Guacira. L. Produzindo sujeitos masculinos e cristãos. In Alfredo Veiga-Neto (Org.). Crí tica pós-estruturalista e educação. Porto Alegre: Sulina, 1995: 83-107.

,Guacira. L. Gênero, sexualidade e educação. Uma perspectiva pós-estruturalista. Petrópolis: Vozes, 1997.

Lüdke, Menga; ANDRÉ, Marli, E.D.A; Pesquisa em Educação: abordagens qualitativas. São Paulo : EPU,1986.

MARCONI, M. de A; LAKATOS, E.M. Metodologia científica. 5.ed. São Paulo:Atlas, 2010, 312.

MATOS, Maria. I. S. Outras histórias: as mulheres e estudos dos gêneros-percursos e possibilidades (Org.). In: . Gênero em debate: trajetória e perspectivas na história Contemporânea. São Paulo: Educ. 1997.

MEYER,Dagmar. Gênero e Educação: teoria e política. In: LOURO, L. G.; NECKEL, F. J.; GOELLNER, V. S. (Orgs.). Corpo, gênero e sexualidade: um debate contemporâneo na educação. Petrópolis: Vozes, 2003. p. 9-27.

MORAES, R. Uma tempestade de luz: a compreensão possibilitada pela análise textual discursiva. Ciência \& Educação, v. 9, n. 2, p. 191-211, 2003.

NEGRINE, Airton. Instrumentos de coleta de informações na pesquisa qualitativa. In: TRIVIÑOS, Nibaldo Silva; NETO, Vicente Molina. (org.) A pesquisa qualitativa na educação física: alternativas metodológicas. Porto Alegre: Ed. Universidade/ UFRGS/ Sulina, 1999. p. 61-93.

Airton. O corpo na Educação Infantil. Caxias do Sul: EDUCS, 2002.

PULCINO, Rachel.; PINHO,R.; e ANDRADE, M., Papéis e identidades de gênero

no cotidiano escolar: a percepção dos/as jovens sobre as relações entre os sexos. Em Aberto, Brasília, v. 27, n. 92, p. 127-146, jul./dez. 2014.

RIBEIRO, P. R. C.; SOARES, G. F.. As identidades de gênero. In: RIBEIRO, Paula Regina Costa (Org.). Corpos, gêneros e sexualidades: questões possíveis para o currículo escolar. Caderno Pedagógico Anos Iniciais. Rio Grande: Editora da FURG, 2007, p.26-29.

ROIZ, Diogo. da S.. A história das relações de gênero, histórias em construção. Rev. Estud. Fem., Florianópolis , $\quad$ v. 19, n. 3, p. 1012-1013, Dec. 
2011;Availablefrom<http://www.scielo.br/scielo.php?script=sci_arttext\&pid=S0104026X2011000300020\&lng=en\&nrm=iso>. access on 13 Maio 2017.

SANTOS, M. P.; PAULINO, M.M. Inclusão em Educação: uma visão geral. In: SANTOS, M. P.; PAULINO, M.M. (Org.). Inclusão em Educação: culturas, políticas e práticas. São Paulo: Cortez, 2006, p. 11-15.

SAFFIOTI, Heleieth.I. B. Rearticulando gênero e classe social. In: OLVEIRA, A.; BRUSCINI, C. (Org.). Uma questão de gênero. Rio de Janeiro: Rosa dos Tempos; São Paulo: Fundação Carlos Chagas, 1992. p. 183-215

SCOTT. Joan. “ Gênero: Uma Categoria Útil para a Análise Histórica.” Traduzido pela SOS: Corpo e Cidadania. Recife, 1990

Joan. O problema de da invisibilidade. In. ESCANDÓN, C.R. (Org.) Gênero e História. México: Instituto Mora/UAM, 1989.

TEIXEIRA, Adla BM; Magistério do gênero: impactos da vida de discentes e docentes;MACHADO, CJS., SANTIAGO, IMFL., and NUNES, MLS., orgs. Gêneros e práticas culturais: desafios históricos e saberes interdisciplinares [online]. Campina Grande: EDUEPB, 2010. 256 p. ISBN 978-85-7879-038-7. Available from SciELOBooks $<$ http://books.scielo.org>p. 38. Acesso em: 21 de maio de 2017.

TEDESCHI, Losandro A. . Leituras de Gênero e interculturalidade;. 1. ed. Dourados - Mato grosso do Sul: EDUFGD, 2013. v. 500. 544

VIANNA, Claudia. P.; UNBEHAUM, Sandra. O gênero nas políticas públicas de educação no Brasil: 1988-2002. Cad. Pesq., São Paulo , v. 34, n. 121, p. 77-104,Apr.2004 $<$ http://www.scielo.br/scielo.php?script=sci_arttext\&pid=S0100-

$15742004000100005 \& \operatorname{lng}=$ en\&nrm=iso>. Acesso 8 Junho 2017. 